\title{
Assessment of various etiological factors of puberty menorrhagia in rural central India
}

\author{
Deepti Gupta, Shradhha Agrawal, Surabhi Gupta
}

\begin{abstract}
Corresponding author: Dr. Deepti Gupta, Associate Professor, Department of Obstetrics and Gynaecology, Index Medical College Hospital and Research Center, Indore (M.P.); Email : drspnagariya@gmail.com
\end{abstract}

Distributed under Attribution-Non Commercial - Share Alike 4.0 International (CC BY-NC-SA 4.0)

\begin{abstract}
Background: Puberty menorrhagia is characterized by bleeding of long duration anywhere between menarche and 19 years. It takes 5-8 years for development of regular menstrual cycle from menarche and during this period the adolescents experience menstrual abnormalities. Objective: The present study was conducted to evaluate the etiologies of puberty menorrhagia in adolescent girls of rural India. Methodology: Retrospective, observational study was carried out over a 2 years period on adolescents presenting with bleeding per vaginum. Permission to use medical records was taken from the medical records. BMI, duration of symptoms, menstrual pattern, ultrasonographic findings, diagnosis, treatment etc. were captured and analysis carried out. Results: The commonest etiology was immaturity of hypothalamic-pituitary ovarian axis, followed by PCOS, endocrine or hematological disorders. Only $25 \%$ were treated with hormonal therapy. Reassurance therapy of adolescent and her parents was found to be of utmost importance. Conclusion: The commonest cause of abnormal bleeding in adolescents is hypothalamic-pituitary ovarian axis immaturity which results in anovulation and then followed by PCOS, endocrine and other disorders requiring diagnostic testing.
\end{abstract}

Keywords: Puberty menorrhagia, abnormal uterine bleeding, menstruation, hormonal therapy, hypothalamic-pituitary ovarian axis, PCOS.

The term puberty refers to the entire span of time during which a human being changes secondary sexual attributes, menstruation starts in the females and changes seen in psychosexual outlook. ${ }^{1}$ There are five major physical characteristics of puberty in females: breast development, pubic hair development, axillary hair growth, height increase and menstrual onset (menarche), through which menarche is a hallmark occurrence throughout the lives of most teenage girls. This marks the change from infancy to puberty. While mechanisms that cause puberty and menarche remain unknown, they depend on the genetics, diet, body weight, and hypothalamic pituitary-ovarian axis maturation.

It can take up to 2 years for the axis to completely mature. It is normal for adolescents to show signs of menstrual irregularities during this period. Puberty menorrhagia is characterized as prolonged bleeding between menarche and 19 years. ${ }^{2}$ The initiation of menstruation does not indicate that ovulation has occurred; early menstrual periods are anovulatory in the majority of cases. Before ovulation, unopposed estrogen results in endometrial proliferation, with resulting menstrual bleeding being severe. The length of the cycle often varies for many years after

Received: $21^{\text {th }}$ April 2020, Peer review completed: $19^{\text {nd }}$ May 2020, Accepted: $20^{\text {th }}$ May 2020.

Gupta D, Agrawal S, Gupta S. Assessment of various etiological factors of puberty menorrhagia in rural central India. The New Indian Journal of OBGYN. 2021; 7(2): 190-95. 
menarche, and it can take around 5-8 years to develop a regular menstrual cycle. Adolescent girls typically experience menstrual abnormalities during this time. ${ }^{3}$

For all cases of puberty menorrhagia, the exclusion of pregnancy, especially an incomplete abortion or ectopic pregnancy, is obligatory. Coagulation disorders and leukemia should be ruled out of chronic anomalous bleeding. For a patient with coagulation disorders, menorrhagia is the only symptom presented with.

One-fourth of the population in developing countries comprises girls under the age of 20 and in India, children under the age of 15 make up around 40 per cent of the total population. ${ }^{4,5}$ It is also recorded that in adolescent girls, irregular uterine bleeding accounts for around 50 per cent of gynecological visits. ${ }^{6}$ Thus in our country, puberty menorrhagia is a common gynecological disorder that leads to morbidity and often mortality in adolescent girls, and menstrual cycle evaluation should be considered an additional vital sign that should be examined in every female adolescent patient coming to hospital. ${ }^{7}$

The prognosis is usually stronger when the abnormal uterine bleeding starts after a time of normal menstruation than when it starts at menarche. For this rural region of central India there are very few studies on puberty menorrhagia and all of the studies have very few participants. The objective of the present study was to examine different etiologies of puberty menorrhagia in rural India adolescent girls.

\section{Materials and methods}

The present retrospective record based study was conducted in the Department of Obstetrics \& Gynaecology, Index Medical College Hospital and Research Centre, Indore (M.P.) from April 1, 2017 to December 31, 2019. Data of all adolescent girls with history of excessive bleeding per vaginum of age between menarche and 19 years either seen on Outpatient basis or were admitted, fulfilling all the inclusion criteria and none of the exclusion criteria were included in the study. The permission to use the data for research purpose was taken from the medical records department. All the care was taken to keep the personal information of the adolescents confidential. Seventy adolescent girls were included in the present study.

All the adolescent girls fulfilling the following inclusion criteria were included in the study:

- Adolescent unmarried girls from age of menarche to 19 years.

- History of excessive bleeding during menses.
- Adolescents girls whose complete information as per the requirement of the study was available in the Records.

Adolescent girls fulfilling the following exclusion criteria were excluded from the study:

- All married adolescent girls attending OPD with obstetric causes of menorrhagia.

- Girls of age more than 20 years with menorrhagia.

- Adolescents girls whose complete information as per the requirement of the study was not available in the records.

Data regarding their age, socioeconomic status, education, age at menarche, menstrual pattern and body mass index were collected from the medical records. Duration and severity of symptoms and severity of anemia was assessed from their available investigations. Menstrual history was recorded in detail which included age at menarche, regularity of cycles in past and present, duration of flow, passage of clots, number of pads used per day, dysmenorrhea and last menstrual day. Complaints of menorrhagia, metrorrhagia and polymenorrhagia were also recorded. Detailed medical history like diabetes mellitus, hypertension, tuberculosis, asthma, bleeding disorders, drug intake and family history also noted. History of other hormonal disorders like hypothyroidism, hyperthyroidism, treatment of PCOS, bleeding disorders was recorded. Information regarding their general physical and clinical examination was noted from the available medical records. Complete blood count, blood group, bleeding and clotting time, random blood sugar level, thyroid and other hormonal levels were also recorded. Findings of ultrasonography of abdomen and pelvis were taken into record. All the data required was captured in the customized proforma designed for the purpose of the study. Age of the adolescent girl, age at menarche, socioeconomic status, education of adolescent girl and her parents, body mass index, menstrual pattern, duration of symptoms, hemoglobin level, ultrasonographic findings, diagnosis and treatment prescribed formed the outcome measures of the study.

The descriptive statistics was presented in the form of number and percentages. Association between duration of symptoms and hemoglobin level and age of adolescent girl and final diagnosis was calculated using Pearson Chi-square test. A p value of $<0.05$ was taken as statistically significant. For the present study, online statistical software graphpad was used for calculating the $\mathrm{p}$ values. 
The New Indian Journal of OBGYN. 2021 (January-June);7(2)

\section{Results}

Majority of the adolescent girls i.e. $48.6 \%$ were in the age group $17-19$ years (Table 1). Approximately $71 \%$ of the

Table 1 : Age wise distribution of adolescent girls

\begin{tabular}{lcc}
\hline Age distribution & No. of girls & Percentage (\%) \\
\hline $11-<14$ & 7 & 10.0 \\
$14-<17$ & 29 & 41.4 \\
$17-<19$ & 34 & 48.6 \\
Total & 70 & 100.0 \\
\hline
\end{tabular}

adolescent girls were having symptoms of menorrhagia of more than 1 year since attainment of menarche (Table 2).

\begin{tabular}{lcc}
\multicolumn{3}{l}{ Table 2 : Relation to menarche } \\
\hline Duration since Menarche & No. of girls & Percentage $(\%)$ \\
\hline$<6$ month & 9 & 12.9 \\
$>6$ month -1 year & 11 & 15.7 \\
$>1$ year -2 years & 20 & 28.6 \\
$>2$ years & 30 & 42.9 \\
Total & 70 & 100.0 \\
\hline $84 \%$ of
\end{tabular}

$84 \%$ of the adolescents in our study belonged to upper lower and lower socioeconomic strata (Table 3 ). Only $2.8 \%$ of the

\begin{tabular}{lcc}
\multicolumn{4}{l}{ Table 3: Socio-economic status of adolescent girls } \\
\hline Socio-economic status & No of patients & Percentage (\%) \\
\hline Upper Class & 0 & 0.0 \\
Upper Middle & 3 & 4.2 \\
Lower Middle & 8 & 11.4 \\
Upper Lower & 31 & 44.3 \\
Lower Class & 28 & 40.0 \\
Total & 70 & 100.0 \\
\hline
\end{tabular}

adolescent girls were illiterate while the rest were from just primary educated to graduates (Table 4 ). Only $5.7 \%$ of the

Table 4 : Education of adolescent girls

\begin{tabular}{lcc}
\hline Education Level & No. of Girls & Percentage (\%) \\
\hline Illiterate & 2 & 2.8 \\
Primary Schooling & 7 & 10.0 \\
Secondary schooling & 58 & 82.9 \\
Graduation & 3 & 4.3 \\
Professional & 0 & 0.0 \\
Total & 70 & 100.0 \\
\hline
\end{tabular}

fathers had done their graduation, while rest of them was just literates, while $35.7 \%$ mothers were illiterate and $64.3 \%$ mothers were just literates (Table 5). $84.3 \%$ of the adolescent Table 5 : Education of the parents of adolescent girls

\begin{tabular}{lcccc}
\hline Education Level & \multicolumn{2}{c}{ Father } & \multicolumn{2}{c}{ Mother } \\
\cline { 2 - 5 } & No. & $\mathbf{( \% )}$ & No. & $\mathbf{( \% )}$ \\
\hline Illiterate & 0 & 0.0 & 25 & 35.7 \\
Primary Schooling & 51 & 72.9 & 35 & 50.0 \\
Secondary schooling & 15 & 21.4 & 10 & 14.3 \\
Graduation & 04 & 5.7 & 0 & 0.0 \\
Professional & 0 & 0.0 & 0 & 0.0 \\
Total & 70 & 100.0 & 70 & 100.0 \\
\hline
\end{tabular}

girls were having normal body mass index (Table 6). Menorrhagia the commonest menstrual pattern was seen in $78.6 \%$ adolescent girls, meno-metrorrhagia was seen in $12.9 \%$ adolescent girls and polymenorrhagia was seen in $8.6 \%$ adolescent girls (Table 7). Majority of the adolescent girls $(48.6 \%)$ had duration of symptoms for more than 1 year (Table 8). In the present study, $21(30 \%)$ adolescent girls were having severe anemia $(\mathrm{Hb}<7 \mathrm{gm} \%)$ and $42(60 \%)$ adolescent girls were having moderate anemia ( $\mathrm{Hb} 7$ to 9 $\mathrm{gm} \%)$. Moderate to severe anemia was seen in majority of

Table 6 : Body Mass Index

\begin{tabular}{lcc}
\hline BMI & No. of Girls & Percentage (\%) \\
\hline$<18.5 \mathrm{~kg} / \mathrm{m}^{2}$ & 5 & 7.4 \\
$18.5-25 \mathrm{~kg} / \mathrm{m}^{2}$ & 59 & 84.3 \\
$>25 \mathrm{~kg} / \mathrm{m}^{2}$ & 6 & 8.6 \\
Total & 70 & 100.0 \\
\hline
\end{tabular}

the adolescent girls whose duration of symptoms was more than 6 months. These adolescent girls were given 1-2 units of blood transfusions. There was no statistically significant

Table 7: Menstrual Pattern

\begin{tabular}{lcc}
\hline Menstrual pattern & No. of Girls & Percentage (\%) \\
\hline Menorrhagia & 55 & 78.6 \\
Meno-metrorrhagia & 9 & 12.9 \\
Polymenorrhagia & 6 & 8.6 \\
Total & 70 & 100.0 \\
\hline
\end{tabular}

association seen between duration of symptoms and hemoglobin levels $(\mathrm{p}=0.07)$, showing that the hemoglobin

Table 8 : Duration of symptoms

\begin{tabular}{lcc}
\hline Duration of symptoms & No. of Girls & Percentage (\%) \\
\hline$<3$ months & 7 & 10.0 \\
3 to 6 months & 6 & 8.6 \\
$>6$ months to 1 year & 23 & 32.9 \\
More than 1 year & 34 & 48.6 \\
Total & 70 & 100.0 \\
\hline
\end{tabular}

levels are not dependent on the duration of symptoms (Table 9). Ultrasonography showed PCOD in $12.9 \%$

Table 9 : Association between hemoglobin level and duration of symptoms

\begin{tabular}{lccccc}
\hline \multirow{2}{*}{ Duration of symptoms } & \multicolumn{4}{c}{ Hemoglobin level (gm \%) } & \multirow{2}{*}{ Total } \\
\cline { 2 - 5 } & $<\mathbf{4}$ & $\mathbf{4 - 7}$ & $\mathbf{7 - 9}$ & $\mathbf{> 9}$ & \\
\hline$<3$ months & 0 & 2 & 4 & 1 & 7 \\
3 to 6 months & 0 & 1 & 2 & 3 & 6 \\
>6 months to 1 year & 2 & 5 & 13 & 3 & 23 \\
> year & 3 & 8 & 23 & 0 & 34 \\
Total & 5 & 16 & 42 & 7 & 70
\end{tabular}

$\chi 2$ value $=15.80, \mathrm{df}=9, \mathrm{p}$ value $=0.07$, Not significant

adolescent girls, fibroid in $4.3 \%$ girls, functional cyst of ovary in $5.7 \%$ girls and endometrial hyperplasia was seen in $2.9 \%$ girls ( Table 10 ). Final diagnosis of primary Table 10 : Ultrasound Finding

\begin{tabular}{lcc}
\hline USG finding & No. of Girls & Percentage (\%) \\
\hline Normal & 52 & 74.3 \\
PCOD & 9 & 12.9 \\
Fibroid & 3 & 4.3 \\
Functional cyst of ovary & 4 & 5.7 \\
Endometrial hyperplasia & 2 & 2.9 \\
Total & 70 & 100.0 \\
\hline dysfunctional uterine & bleeding was made in $72.9 \%$
\end{tabular}
dysfunctional uterine bleeding was made in $72.9 \%$ adolescent girls, PCOD in $12.9 \%$ adolescent girls, fibroid in $4.3 \%$ adolescent girls and hypothyroidism in $10.0 \%$ adolescent girls (Table 11). In our study higher incidence of dysfunctional uterine bleeding seen in the adolescent girls of age between 11-14 years and 14-17 years, while higher incidence of PCOD was seen in 17-19 years. There was a statistically significant association seen between age of the adolescent girls and final diagnosis $(\mathrm{p}=0.001)$, showing that 
the final diagnosis is dependent on the age of the adolescent girls ( Table 12 ). The adolescents having fibroid and

Table 11: Final Diagnosis

\begin{tabular}{lcc}
\hline Final diagnosis & No. of Girls & Percentage (\%) \\
\hline Primary DUB & 51 & 72.9 \\
PCOD & 9 & 12.9 \\
Fibroid & 3 & 4.3 \\
Hypothyroidism & 7 & 10.0 \\
Total & 70 & 100.0 \\
\hline
\end{tabular}

hypothyroidism (total $\mathrm{n}=10$ ) were included in dysfunctional uterine bleeding making the total adolescents in this group

Table 12: Association between age and final diagnosis

\begin{tabular}{lcccc}
\hline Final Diagnosis & \multicolumn{2}{c}{ Age of Adolescent Girls (years) } & \multirow{2}{*}{ Total } \\
\cline { 2 - 4 } & $\mathbf{1 1 - < \mathbf { 1 4 }}$ & $\mathbf{1 4 - < \mathbf { 1 7 }}$ & $\mathbf{1 7 - < \mathbf { 1 9 }}$ & \\
\hline DUB & 25 & 29 & 7 & 61 \\
PCOD & - & 2 & 7 & 9 \\
Total & 25 & 31 & 14 & 70 \\
\hline
\end{tabular}

$\chi^{2}$ value $=22.06, \mathrm{df}=2, \mathrm{p}$ value $=0.001$, Significant

equal to 61. Majority of patients were treated by nonhormonal treatment by reassurance, hematinics and tranexamic acid (approximately 65\%) while 25\% were treated by hormonal treatment. $10 \%$ adolescent girls who were diagnosed with hypothyroidism were treated with thyroid supplementation (Table 13).

Table 13: Treatment received

\begin{tabular}{lcc}
\hline Type of treatment given & $\begin{array}{c}\text { No. of } \\
\text { Girls }\end{array}$ & $\begin{array}{c}\text { Percentage } \\
(\%)\end{array}$ \\
\hline Reassurance \& Hematinic & 15 & 21.4 \\
Hematinic \& Tranexamic Acid & 30 & 42.9 \\
Hematinic, Tranexamic Acid \& Progestorone & 2 & 2.9 \\
Hematinic, Tranexamic Acid \& OCP & 16 & 22.9 \\
Hematinic, Tranexamic Acid \& Thyroxine & 7 & 10.0 \\
Total & 70 & 100.0 \\
\hline
\end{tabular}

\section{Discussion}

WHO describes adolescence as a time between 11-19 years of age. It is the period of human growth which extends from childhood immaturity to adult physical and psychological maturity. Menarche is a seminal occurrence in young girls' lives. Occasionally menarche accompanied by irregular uterine bleeding that lasts until 19 years is called menorrhagia of puberty.

Majority of the adolescent girls $(48.6 \%)$ in our study are in the age group 17-19 years, followed by $41.4 \%$ adolescent girls in the age group 14-17 years. The results of our study corroborate with the studies done by Khosla et al $(2010)^{\mathbf{8}}$ who reported that $55 \%$ of their study participants belonged to mid to late adolescence and the study done by Joshi et al $(2012)^{9}$ also reported that $92 \%$ of their participants were in the mid to late adolescence. This shows the puberty menorrhagia is more common in adolescent girls more than 14 years. In majority of the adolescent girls in our study $(71.5 \%)$ the duration of symptoms is more than 1 year since their attainment of menarche.
In our study $44.3 \%$ adolescent girls belonged to upper lower class and $40.0 \%$ belonged to lower class. Majority of the adolescent girls belong to upper lower and lower class strata of the society. Studies done by Rao et al (2004) ${ }^{2}$ and Koranne et al (2014) ${ }^{\mathbf{1 0}}$ reported that there majority of the adolescent girls also belonged to lower socioeconomic status, which is comparable to our study findings. This shows that adolescent girls belonging to these two socioeconomic strata have higher incidence of puberty menorrhagia.

Only $2.8 \%$ adolescent girls were illiterate, $4.3 \%$ had done their graduation, while $92.9 \%$ adolescent girls were just literates. Majority of the adolescent girls in our study are just literates. Study done by Gottapu et al (2014) ${ }^{\mathbf{1 1}}$ reported literacy rate of $54 \%$ in their study which is comparatively lower in Gottapu et al (2014) study in comparison to the present study. $94.3 \%$ fathers and $64.3 \%$ mothers had done their primary and secondary education, while $35.7 \%$ mothers were illiterate. Poor educational status could be cause for late presentation of adolescent girls with symptoms of menorrhagia to the hospitals.

$84.3 \%$ adolescent girls were in the normal BMI group, while $8.6 \%$ were in the overweight BMI group. Majority of the adolescent girls in our study are in the normal BMI group. According to the study done by Peter et al (2017) ${ }^{\mathbf{1 2}}$ menorrhagia was found to be highest in the normal BMI group adolescent girls, which is comparable to our study results.

In our study, menorrhagia seen in $78.6 \%$ adolescent girls is the most common menstrual pattern, followed by menometrorrhagia and polymenorrhagia. Study by Kazi et al $(2014)^{13}$ reported an incidence of menorrhagia in $50 \%$ of the adolescent girls. Our study results are in concordance with the results of Kazi et al (2014). In the present study, 32.9\% adolescent girls had duration of symptoms between 6 months to 12 months and $48.6 \%$ adolescent girls had duration of more than 1 year. Majority of the adolescent girls in our study are having duration of symptoms more than 1 year. Our study results are in corroboration with the study done by Gillani et al (2012) ${ }^{1}$ who reported that $58 \%$ adolescent girls had duration of symptoms of more than 1 year and also study done by Khosla et al $(2010)^{\mathbf{8}}$ supports our study, who reported that $44 \%$ had symptoms of duration more than 1 year in their study. While the study done by Rao et al $(2004)^{2}$ reported that $62 \%$ of the adolescent girls in their study had a duration of symptoms of less than 6 months, which is contrary to our findings. The reason for late presentation in 
our study could be due to unawareness about puberty menorrhagia, this could be due to lack of education.

In the present study, $60 \%$ adolescent girls had moderate anemia and $30 \%$ had severe anemia. Only $10 \%$ adolescent girls in our study are having normal hemoglobin level. Our study results are comparable with the study done by Rao et al (2004). ${ }^{2}$ Our study found no significant association between hemoglobin level and the duration of symptoms of menorrhagia $(\mathrm{p}=0.07)$. PCOD was seen in $12.9 \%$ adolescent girls, fibroid in $4.3 \%$, functional cyst of ovary in $5.7 \%$ and endometrial hyperplasia in $2.9 \%$ adolescent girls. PCOD and functional cyst of ovary is the commonest USG findings in our study. Similar findings were reported by the studies done by Gillani et al (2012) ${ }^{1}$ who reported an incidence of PCOD to be $8.6 \%$, Joshi et al (2012) $)^{9}$ reported it to be $14 \%$ and Kazi et al $(2014)^{13}$ reported it as $9 \%$ in their study. In the present study primary dysfunctional uterine bleeding was seen in $72.9 \%$ adolescent girls, PCOD in $12.9 \%$, fibroid in $4.3 \%$ and hypothyroidism in $10 \%$. Majority of the adolescent girls are having primary dysfunctional uterine bleeding. Study done by Chaudhury et al (2007) $)^{14}$ found dysfunctional uterine bleeding in $71 \%$ adolescent girls. Rao et al $(2004)^{2}$ found dysfunctional uterine bleeding in $80 \%$, PCOD in $2.8 \%$ and hypothyroidism in $5.7 \%$ adolescent girls. Roychowdhury et al $(2008)^{15}$ found dysfunctional uterine bleeding in $61 \%$, PCOD in $3 \%$, fibroid in $3 \%$ and hypothyroidism in $9.3 \%$ adolescent girls. Our results of dysfunctional uterine bleeding are comparable with the studies done by Chaudhuri et al (2007), ${ }^{14}$ Rao et al (2004) ${ }^{2}$ and Roychowdhury et al (2008). ${ }^{15}$ While our study results of PCOD are much higher than reported by these authors. In adolescents $95 \%$ of cases of anovulation are due to the immaturity of HPO axis. ${ }^{9}$ These adolescents lack the positive feedback mechanism necessary to initiate an LH surge and subsequent ovulation despite normal follicular estrogen level. In our study we did not come across bleeding diathesis. In our study, we found a significant association between age and final diagnosis ( $p=0.001$ ), showing the final diagnosis is dependent on the age of the adolescent girls.

$42.9 \%$ adolescent girls received hematinic and tranexamic acid, $22.9 \%$ received hematinic, tranexamic acid and OCP, $21.4 \%$ received reassurance and hematinic. Majority of the adolescent girls have received hematinic and tranexamic acid in our study. $63 \%$ in this study group responded well with use of tranexamic and mefenamic acid during menstruation along with oral iron therapy. Our study results are in corroboration with the study done by Royal
College Of Obstetrician and Gynaecologist (1999) ${ }^{16}$ also recommended tranexamic acid and mefenamic acid as first line drugs for menorrhagic women who either do not need contraception, or choose non-hormonal treatment. The aim of treatment in these adolescent patients is to regulate menstruation by stabilizing the endometrium and treating the hormonal alterations. The main stay treatment is reassurance that it is a self-limiting problem, followed by hematinics, tranexamic acid and NSAIDS during the menstrual cycle.

In our study menorrhagia due to PCOS was $12.85 \%$, while study done by Rao et al (2004) $)^{2}$ and Roychowdhury et al $(2008)^{15}$ found incidence to be $2.8 \%$, and $3.07 \%$ respectively, which is comparatively low in comparison to the present study. COCP's were chosen as first line therapy along with hematinics in $22.85 \%$ while progesterone alone given in only $2.85 \%$ patients. In Roychowdhury et al (2008) ${ }^{15}$ study, $44.61 \%$ had received non-hormonal and $26.15 \%$ had received hormonal therapy. In the present study $10 \%$ were found to be hypothyroid and responded well to thyroid supplementation. Mukherjee et al (1986) ${ }^{17}$ in their study of 70 cases of pubertal menorrhagia found the incidence of hypothyroidism to be $7.15 \%$.Hypothyroid teenagers have milder symptoms than older patients. The cause of the excessive bleeding remains the subject of speculation in them. Although rare, uterine pathology such as fibroids and polyps may lead to abnormal uterine bleeding. ${ }^{17}$ In our study, $4.28 \%$ was having uterine fibroid on ultrasonography, was treated conservatively with hematinics, tranexamic acid and analgesics without any surgical interventions. Two patients had relief from menorrhagia and one patient was treated with GnRH agonists to which she responded well.

\section{Conclusion}

The most common etiology of abnormal bleeding in adolescents is immaturity of the hypothalamic-pituitary ovarian axis that results in anovulation followed by PCOS, endocrine, or hematological disorders that require targeted diagnostic testing. If abnormal uterine bleeding begins after a period of regular menstruation, the prognosis is better than when it begins at menarche. Individualization of each case, detailed history, physical examination, base line workup and timely hospitalization are critical to handling each case. To treat puberty menorrhagia, reassurance, therapy of adolescent girls and their parents about menstruation physiology is of utmost importance. Progesterone-only or combination hormone therapy with OCP is important treatment when patients do not respond to standard, supportive care. Regular 
The New Indian Journal of OBGYN. 2021 (January-June);7(2)

follow-up, healthy diet, and iron therapy needed in all menorrhagic puberty patients.

\section{Conflict of interest: None. Disclaimer: Nil.}

\section{References}

1. Gillani S, Mohammad S. Puberty Menorrhagia: causes and management. Journal of Medical Sciences (Peshawar). 2012 Jan; 20(1):15-8.

2. Rao S, Pawar V, Badhwar VR, Fonseca MN. Medical intervention in puberty menorrhagia. Bombay Hospital Journal. 2004; 46(2): 1-6.

3. Edmonds DK. Gynecological disorders of childhood and adolescence. In: Edmonds DK, editor. Dewhurst's Textbook of Obstetrics and Gynecology, 8th Ed. Oxford: Blackwell Publishing; 2007. p. 480-6.

4. Krishna UR, Salvi V. Adolescent and paediatric gynaecological problems. In: Ratnam SS, Rao KB, Arulkumaran S. Eds. Obstetrics \& Gynaecology for Postgraduates. Madras: Orient Longman; 1999.

5. Park K. Preventive Medicine in Obstetrics, Paediatrics and Geriatrics. In: Park K, ed. Park's Textbook of Preventive and Social Medicine. 23th ed. New Delhi: Bhanot Publishers; 2015.

6. Caufriez A. Menstrual disorders in adolescence: Pathophysiology and treatment. Horm Res. 1991; 36:156-9.

7. ACOG Committee on Adolescent Health Care. ACOG Committee Opinion No. 349, November 2006: Menstruation in girls and adolescents: using the menstrual cycle as a vital sign. Obstet Gynecol. 2006;108:1323-8.

8. Khosla AH, Devi L, Goel P, Saha PK. Puberty menorrhagia requiring inpatient admission. JNMA J Nepal Med Assoc. 2010 Apr-Jun; 49(178):112-6.

9. Joshi S, Chella H, Shrivastava D. Study of puberty menorrhagia in adolescent girls in rural set-up. Journal of SAFOG. 2012; 4(2):110-2.
10. Koranne PS, Wahane AR. Puberty menorrhagia in modern era: analysis in a tertiary care centre. Int $\mathrm{J}$ Reprod Contracept Obstet Gynecol. 2014 Sep; 3(3): 622-6.

11. Gottapu K, Sharanya G. A study of demographic profile and evaluation of menorrhagia. Indian Journal of Applied Research. 2014; 4(1): 430-4.

12. Peter AB, Ocholi SG. Body mass index and incidence of menorrhagia among adolescent female undergraduate students in Nigeria. International Journal of Medical and Health Research. 2017; 3(7): 75-9.

13. Kazi SB, Hamida B, Kishwar S, Ferdous AB, Dipi B. Clinical evaluation of puberty menorrhagia - A study of fifty cases. J Med Sci Res. 2014;74:1063-70.

14. Chaudhury S, Bhattacharya PK, Sarkar A. Study of adolescent menorrhagia. Indian Medical Journal. 2007;101(5):161-4.

15. Roychowdhury J, Chaudhuri S, Sarkar A, Biswas PK. A study to evaluate the aetiological factors and management of puberty menorrhagia. Online J Health Allied Scs. 2008; 7(1); 5.

16. Royal College of Obstetricians and Gynaecologists. The initial management of menorrhagia. RCOG Evidence Based Clinical Guidelines No.1. London; 1999.

17. Mukherjee J, Chowdary NNR. A review of 70 cases of puberty menorrhagia. Journal of Obstetrics and Gynaecology of India. 1986; 36(1):121-5.

\section{Deepti Gupta ${ }^{1}$, Shradhha Agrawal ${ }^{2}$, Surabhi Gupta ${ }^{3}$}

${ }^{1}$ Associate Professor, Department of Obstetrics and Gynaecology, Index Medical College Hospital and Research Center, Indore (M.P.), India; ${ }^{2}$ Third Year Postgraduate Resident, Department of Obstetrics and Gynaecology, Index Medical College Hospital and Research Center, Indore (M.P.), India; ${ }^{3}$ Third Year Postgraduate Resident, Department of Obstetrics and Gynaecology, Index Medical College Hospital and Research Center, Indore (M.P.), India. 